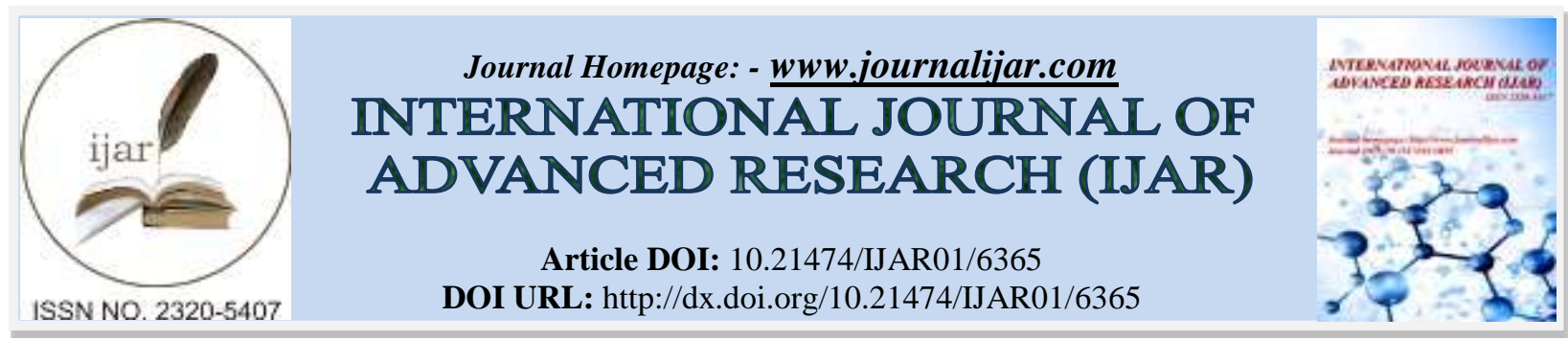

RESEARCH ARTICLE

\title{
AN EVALUATIVE STUDY TO ASSESS THE EFFECTIVENESS OF LEMON JUICE ON PREGNANCY INDUCED HYPERTENSION AMONG ANTENATAL MOTHERS IN DOMMASANDRA PHC, BANGALORE.
}

Mrs. Uma Parvathi.

Associate professor krupanidhi college of nursing affiliated to rguhs, bangalore.

\section{Manuscript Info}

Manuscript History

Received: 20 November 2017

Final Accepted: 22 December 2017

Published: January 2018

Keywords:-

Effectiveness, Lime juice, Pregnancy

Induced Hypertension, Antenatal mother.

\section{Abstract}

Hypertension is one of the most important public health challenges in worldwide. Uncontrolled hypertension can cause mild and severe consequences in Pregnancy and the diet plays an important role in maintaining health, as an alternative therapy a citrus fruit like lemon causes clinically significant interactions with a variety of drugs including calcium antagonists. Lemon juice contains vitamin $\mathrm{c}$ which reduces systolic and diastolic blood pressure. Regular practice of ingestion of lemon juice would have a positive impact in controlling blood pressure. OBJECTIVES:To determine the effect of lemon juice on selected physiological parameters among PIH mothers in experimental group .To compare the physiological parameters of PIH mothers in both experimental and control group.To determine the association between physiological parameters and selected demographic variables among PIH mothers.METHODS: A quasi experimental pre-test and post test design with control group was used for this study. A sample of $30 \mathrm{PIH}$ mother between the age group of 20 - 25 were selected by using purposive sampling technique and 15 mothers each were assigned randomly to the experimental and control group. Base line data, mercury sphygmomanometer, stethoscope were used to obtain the data .RESULT: Result of study revealed that there was significant deference between mean pre test and post test score of systolic blood pressure at $1^{\text {st }}$ day( Mean=138.66) and $5^{\text {th }}$ day ( Mean=126), diastolic blood pressure at $1^{\text {st }}$ day $\left(\right.$ Mean=90) and $5^{\text {th }}$ day ( Mean=80 ) among experimental group. The obtained't' value of systolic and diastolic mean for pre test and post test (5.025 and 5.076) was greater than the table value, that inferred that Lime juice is effective in reducing Pregnancy Induced Hypertension.CONCLUSION:The finding of the study concluded that Lime juice intake is effective during Pregnancy Induced Hypertension in reducing Blood Pressure.

\section{Introduction:-}

"A YEAR FROM NOW YOU WILL WISH YOU HAD STARTED TODAY” 
Pregnancy and childbirth are natural processes in women .However, the reality is that women and children suffer and dies as a consequence of child bearing process. Hypertension is the most common medical Problem encountered in Pregnancy and remains an important cause of maternal and fetal morbidity and mortality ${ }^{5}$

In a multi centre study approximately $30 \%$ of hypertensive disorder of pregnancy was due to chronic hypertension where $70 \%$ of the cases were diagnosed as gestational induced hypertension.

According the report of National centre of health statistic hypertension complicate around 37\% of pregnancy in the USA and $16 \%$ of pregnancy related death from complication of pregnancy induced hypertension. According to global health result overall 3-10\% of world is estimated to have pregnancy induced hypertension among which black women are at risk of 3 times more than white women to die from pre-eclampsia. It is common in developing countries.

The reported incidence of hypertension disorder of pregnancy in India was 5.38\% while pre-eclampsia, eclampsia accounted for $44 \%$ and $40 \%$ leading to $5.55 \%$ maternal mortality rate and $37.5 \%$ prenatal death rate.

According to study of clinico-epidemiological a report of global statistic of Karnataka, Bangalore show prevalence rate of pregnancy induced hypertension among women is $13 \%$.

In a multicentre study approximately $30 \%$ of hypertension disorder of pregnancy were due to chronic hypertension while $70 \%$ of the cases were diagnosed as pre-eclampsia. The three most common form of hypertension are acute gestational hypertension, pre-eclampsia and chronic essential hypertension.

Five classes of hypertension disorders were identified according to latest classification described by national high blood pressure education working group including pre-eclampsia, eclampsia transient hypertension in pregnancy gestational hypertension, and chronic hypertension ${ }^{5}$

Hypertension in pregnancy also referred as PIH or gestational hypertension.PIH is defined as "A blood pressure of $\geq$ $140 / 90 \mathrm{mmHg}$ on two occasions more than a part of 4hours in a pregnant lady of more than 20 weeks of gestation ${ }^{3}$

Pre-eclampsia is multi-system disorder of unknown etiology unique to pregnancy .Pre-eclampsia can present as HELLP syndrome that is haemolysis elevated liver enzymes and low platelet count or eclampsia that is occurrence of convulsion that cannot be attribute to other etiologic factors. Eclampsia is reported to be associated with a maternal mortality rate of $0.5-10 \%$ usually requiring high quality intensive care ${ }^{2}$

Hypertension can be managed by pharmacological and non -pharmacological treatment. The drug used for treating hypertension includes diuretics, adrenergic inhibitors, direct vasodilators etc ${ }^{3}$ and they have their own hyperuricemia, hypotension hypocalcemia as side effect. The non pharmacological management includes lifestyle modification as well as alternative therapy like exercises, diet, reduce weight, stress management, physical activity, moderation of alcohol consumption and lemon juice as home remedies.

\section{Objectives Of The Study:-}

1. To determine the effect of lemon juice on selected physiological parameters among PIH mothers in experimental group

2. To compare the physiological parameters of PIH mothers in both experimental and control group

3. To determine the association between physiological parameters and selected demographic variables among PIH mothers

\section{Methodology:-}

An evaluation research approach was adopted, Quasi experimental: Pre test-Post test design was selected for this study, setting of the study was Dommasandra Primary Health Center ,Bangalore. Study population consist of all the Antenatal mother more than 20 week of gestation with PIH got admitted or came for safe confinement in selected PHC.The sample for the present study was 30 Antenatal Mother within 3015 in control group and 15 in experimental group where lime juice was given .Prior to data collection official permission was obtained .Informed consent was obtained from the Antenatal Mothers. Pre- test was given to the entire sample (Control group and 
Experimental group) by checking the Blood pressure. Thereafter lime juice was administer to the experimental group for continuous 5 Days .After 5 days Post Test was conducted .The data were tabulated and analyzed manually.

\section{Results:-}

I : Effect of lime juice on the level of BP among PIH mothers in experimental group:

Table I:- Comparison of mean, standard deviation of systolic, and diastolic blood pressure among PIH mothers at $1^{\text {st }}$ and $5^{\text {th }}$ day in experimental group by administrating lime juice.

\begin{tabular}{|c|c|c|c|c|c|c|}
\hline \multirow[t]{3}{*}{ Variables } & \multicolumn{4}{|c|}{ Experimental Group } & \multirow[b]{3}{*}{ 't'VALUE } & \multirow[t]{3}{*}{ Inference } \\
\hline & \multicolumn{2}{|c|}{ Pre-test $\left(1^{\text {st }}\right.$ day $)$} & \multicolumn{2}{|c|}{ Post -test $\left(5^{\text {th }}\right.$ day $)$} & & \\
\hline & Mean & SD & mean & SD & & \\
\hline $\begin{array}{l}\text { SYSTOLIC } \\
\text { BP }\end{array}$ & 138.66 & 7.432 & 126 & 6.324 & 5.025 & Significant \\
\hline $\begin{array}{l}\text { DIASTOLIC } \\
\text { BP }\end{array}$ & 90 & 6.546 & 80 & 3.779 & 5.076 & Significant \\
\hline
\end{tabular}

T28 at $0.05=2.05$.

The result shows there was a significant between pre-test and post-test score of experimental group

The obtained ' $t$ ' value of systolic and diastolic blood pressure (5.025 and 5.076) is greater than the table value, its inferred that Lime juice is effective in reducing Pregnancy Induced Hypertension.

II. Comparision of BP of PIH mother in experimental and control group.

Table II:- Comparison mean, standard deviation of systolic and diastolic blood pressure among PIH mothers in experimental and control group.

\begin{tabular}{|c|c|c|c|c|c|c|c|c|}
\hline \multirow[t]{3}{*}{ Variables } & \multicolumn{4}{|c|}{ Experimental group } & \multicolumn{4}{|c|}{ Control Group } \\
\hline & \multicolumn{2}{|c|}{ Pre test } & \multicolumn{2}{|c|}{ Post test } & \multicolumn{2}{|c|}{ Pre test } & \multicolumn{2}{|c|}{ Post test } \\
\hline & Mean & SD & Mean & SD & mean & SD & mean & SD \\
\hline Systolic & 138.6 & 7.432 & 126 & 6.324 & 139.33 & 7.463 & 132.667 & 4.577 \\
\hline Dias & 90 & 6.546 & 80 & 3.779 & 85.33 & 8.337 & 83.333 & 6.172 \\
\hline
\end{tabular}

The finding revealed that there was a significant reduction in post test and standard deviation of the subject in experimental group for all the Blood Pressure level, while in the control group there was a slight reduction in the post test.

Table III:- Comparison of mean, standard deviation of systolic, diastolic blood pressure of post test among PIH mothers at $5^{\text {th }}$ in the experimental group and control group:

\begin{tabular}{|l|l|l|l|l|l|l|}
\hline \multirow{2}{*}{ variables } & Experimental Group & \multicolumn{2}{|c|}{ Control Group } & 't' & \multirow{2}{*}{ Inference } \\
\cline { 2 - 5 } & Mean & SD & Mean & SD & \\
\hline 1)Systolic & 126 & 6.324 & 132.667 & 4.577 & 3.308 & Significant \\
\hline 2)Diastolic & 80 & 3.779 & 83.333 & 6.172 & 1.784 & Not significant \\
\hline
\end{tabular}

T28 at $0.0=2.05$,

The result showed that there was a significant difference between post test mean score of systolic blood pressure but there was no significant difference between post test mean score of diastolic Blood pressure. 


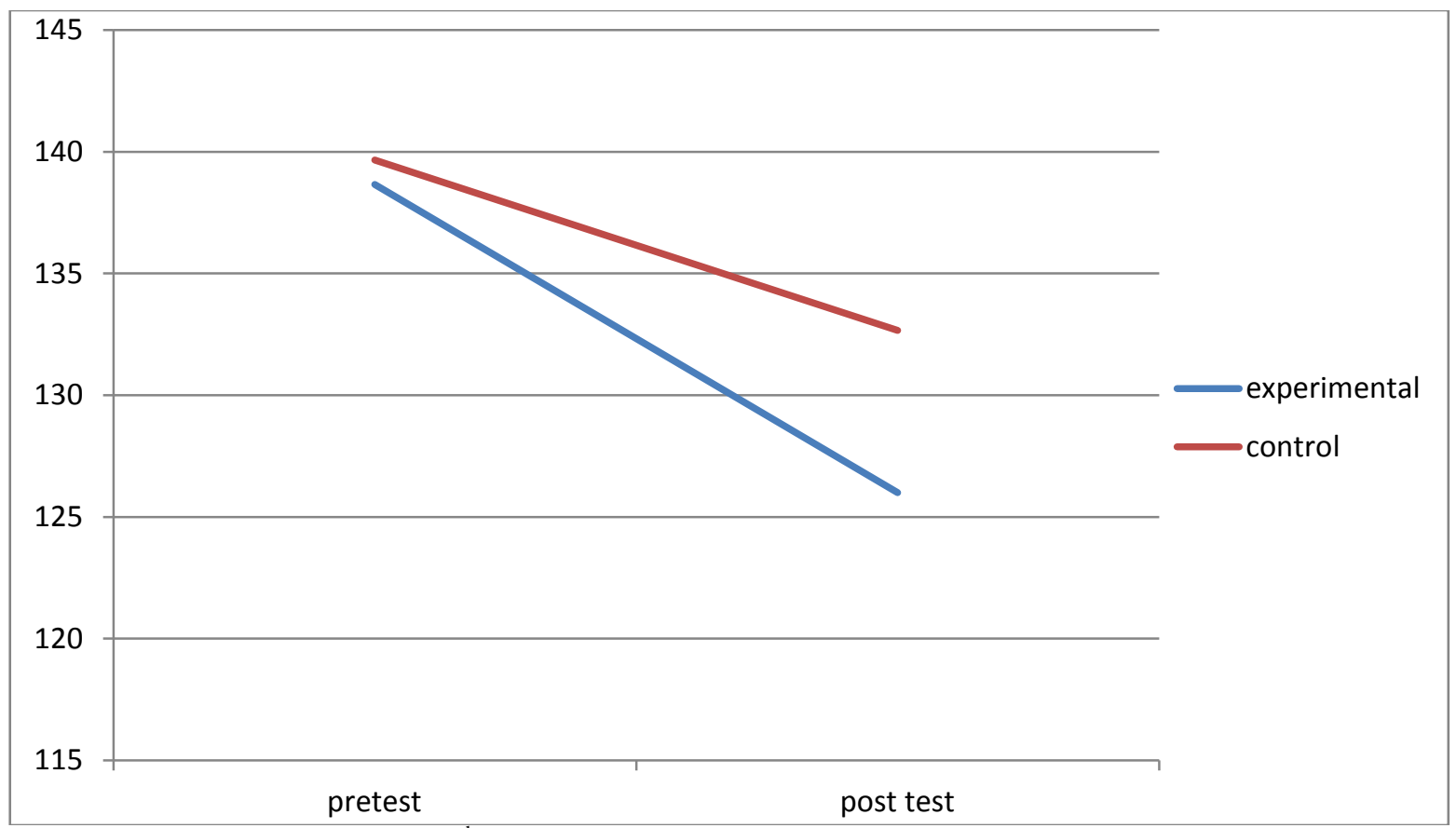

Fig1:- comparison of pre-test and $5^{\text {th }}$ post test of systolic blood pressure among PIH mother in Experimental and control group.

Table IV (a):- Association between selected demographic variables and systolic blood pressure in the experimental group.

$\mathrm{n} 1=15$

\begin{tabular}{|c|c|c|c|c|c|}
\hline \multirow[t]{2}{*}{ Demographic variables } & \multicolumn{2}{|c|}{ Systolic $B P$} & \multirow[t]{3}{*}{$x^{2}$} & \multirow[t]{3}{*}{ df } & \multirow[t]{3}{*}{ Inference } \\
\hline & \multirow{2}{*}{ Above mean } & \multirow{2}{*}{\begin{tabular}{|l|} 
Below mean \\
\end{tabular}} & & & \\
\hline Age in years & & & & & \\
\hline $20-30$ & 7 & 5 & \multirow[t]{2}{*}{8.26} & \multirow[b]{2}{*}{1} & \multirow[b]{2}{*}{$* \mathrm{NS}$} \\
\hline $30-40$ & 1 & 2 & & & \\
\hline \multicolumn{6}{|l|}{ Dietary pattern } \\
\hline vegetarian & 1 & 3 & \multirow[b]{2}{*}{0.45} & \multirow[b]{2}{*}{1} & \multirow[b]{2}{*}{ *NS } \\
\hline Non- vegetarian & 5 & 6 & & & \\
\hline
\end{tabular}

$\left(x^{2}=3.84, \mathrm{p}<0.05\right)$

*NS - Non significant

The result shows that the computed $x^{2}$ value for age and dietary pattern was lower than the table value of 0.05 level significant and it is inferred that there is no significant association with systolic blood pressure in the experimental group.

Table IV (b):- Association between selected demographic variables and diastolic blood pressure in the experimental group.

\begin{tabular}{|c|c|c|c|c|c|}
\hline \multirow{2}{*}{$\begin{array}{l}\text { Demographic } \\
\text { variables }\end{array}$} & \multicolumn{2}{|c|}{ Diastolic BP } & \multirow[b]{2}{*}{$x^{2}$} & \multirow[t]{2}{*}{$\mathrm{df}$} & \multirow[t]{2}{*}{ Inference } \\
\hline & $\begin{array}{l}\text { Above } \\
\text { mean }\end{array}$ & $\begin{array}{l}\text { Below } \\
\text { mean }\end{array}$ & & & \\
\hline \multicolumn{6}{|l|}{ Age in years } \\
\hline $20-30$ & 4 & 0 & 0.383 & 1 & $* \mathrm{NS}$ \\
\hline $30-40$ & 10 & 1 & & & \\
\hline \multicolumn{6}{|l|}{ Dietary pattern } \\
\hline vegetarian & 11 & 1 & & & \\
\hline Non-vegetarian & 3 & 0 & 0.2677 & 1 & $* \mathrm{NS}$ \\
\hline
\end{tabular}

*NS-NON SIGNIFICANT 
The result shows that the computed $x^{2}$ value for age and dietary pattern was lower than the table value at 0.05 level significance, and it is inferred that there is no significant association with diastolic blood pressure in the experimental group.

\section{Discussion:-}

The finding of study revealed that the majority of subjects in the experimental group (73.34\%) and control group $(66.66 \%)$ were in the age group of 20-25 years and its revealed that the prevalence of PIH was $(64.5 \%)$ more among antenatal mother who has 20-30 years of age and the subjects in the experimental group (66.66\%) and control group $(60 \%)$ were the primi gravida mothers which suggests the PIH was more common among primi gravida mother and also revealed that the majority of the subjects in the experimental group (73.34\%) and control group $(73.4 \%)$ were belong to non-vegetarians which shows PIH was common in non-vegetarians.

The finding of present study identified that, there is a significant difference between pre-test and post test score of blood pressure of subjects in the experimental group at 0.05 level of significant on the first and fifth days. Its inferred that lemon juice was effective in reducing the blood pressure of the subject in the experimental group..

Analysis of study findings identify that there is significant difference between the post test mean of subject in the experimental and control group at 0.05 level of significance on the first and fifth day and is inferred that lemon juice was effective in reducing $\mathrm{BP}$

The present study revealed there is no the association between the demographical variables such as age and dietary pattern.

\section{Conclusion:-}

The finding of the study revealed that lemon juice ingestion was effective in reducing BP among Antenatal mother but there was no association between BP and demographical variables like age, and dietary pattern .PIH cannot be cure by lemon juice ingestion but it can be control effectively by administering lemon juice with medication or alone .A good control on all this, one can have a better quality life

\section{Implication:-}

The findings of the study have several implications for nursing in the area of education, administration, practice and research. Each of these areas addressed individually by the investigator are given below.

Nursing education

Hypertension is one of the common medical complications of pregnancy and contributes significantly to maternal and peri-natal mortality and morbidity. The uses of alternative and complementary therapies are increasing in popularity. Lemon juice is beneficial and cost effective intervention to the antenatal mothers. Nurse educator need to highlight the non pharmacological measures in BP control and to train the students in skill based learning and to emphasis on home care management. The nurse educator has the responsibility to update knowledge of students and nurses .

\section{Nursing practice:-}

The nurse play a vital role in health care delivery system as she works in immediate environment with the patient caring for the individual in the holistic manner. Professional nurses are increasingly offering patient a variety of choices of therapy as a part of a comprehensive care plan. Lemon juice is a cost effective intervention which is easily available with no side effect. It is simple to administer and cheaply available. By using the lime juice person will be able to reduce the blood pressure. Using current research finding nurses can use lemon juice as an effective intervention in their practice, mainly in community settings.

\section{Nursing administration:-}

Nursing administration are in the key position to formulate policies and the execution of quality nursing based on research finding with necessary changes in nursing education and practice. They should develop protocols and can develop standards for including lime juice as a management of pregnancy induced hypertension. In in-service education for staff nurse could be provided on lemon juice ingestion to reduce PIH in antenatal mothers.

Nursing research 
A profession seeking to improve the practice of its member and to enhance its profession strives for the continuous development of a relevant body of knowledge. Lemon juice showed a significant reduction in blood pressure. There is great need for the extensive and intensive research in the area of complimentary therapy to reduce blood pressure $\mathrm{n}$ PIH mothers. The finding of the study need to be disseminated through publication so that the utilization of such research finding is encouraged.

\section{Limitation:-}

1. The study was confined to antenatal mothers who have PIH available in Dommasandra PHC.

2. The study is limited to a sample size of 15 in experimental and 15 in control group which restrict the generalization of the study.

\section{Recommendation:-}

On the bases of the findings of the study following recommendation have been made from the further study.

1. The study can be replicated on the larger samples for the generalization of finding.

2. A similar study can be conducted in different hospital setting.

3. A similar study can be conducted for a longer duration.

4. A similar study can be done focusing on different age group.

5. A comparative study could be conducted between lemon juice ingestion and garlic ingestion

6. The findings of the study could be used by all health personnel and administrators to formulate policies and implements the measures to reduce the blood pressure in PIH.

\section{Summary:-}

This chapter dealt with the conclusion, nursing implication, limitation and the recommendation of the study.

\section{Bibliography:-}

1. Adele Pillitere. Maternal and Child Health Nursing. $6^{\text {th }}$ edition , Lippincott \& wilkins company 2010 pg-575.

2. Annamma Jacob, A Comprehensive Textbook of Midwifery. Jaypee Brothers Medical publisher (P) LTD $2^{\text {nd }}$ edition reprint 2009.

3. D.C Dutta, Textbook of obstretricsJaypee Brothers Medical Publishers(p) Ltd,New Delhi $7^{\text {th }}$ Edition reprint 2013 Pg no-219.

4. K Park. The Text Book of Preventive and Social Medicine. $12^{\text {th }}$ edition ,Banarsidas Bhanot Nagpur Road Pg no $-683$

5. Shirish N Daftary and Sudip Chakravarti

6. Mannual of Obstetrics, Elsevier a division of Reed Elsevier India (P) LTD $2^{\text {ND }}$ edition reprint 2007 Pg no -9.

7. Suresh k Sharma. Nursing Research and Statistics, Published by Elsevier, a division of Reed Elsevier India Private limited Pg no -375 to 376

8. Danish N, Fawad A, Abbasi N. Assessment of pregnancy outcome in primi gravida, 2010 Apr-Jun22(2) 23-5 Pg no -111

9. Jaya Priya .J. Deep Breathing Exercise and Hypertension: a Pilot Study of Indian MSC (dissertation).Karnataka: Rajiv Gandhi University: 2014

10. Kausik R. Blood Pressure before and after abdominal breathing exercise among hypertensive patient 2015 Page no ( 8 )

11. Ramesh K, Sangeetha Gandhi and Vishwas Rao. Socio- Demographic and other Risk Factors of Pre- Eclampsia 2014 Volume 8 Page no (111)

12. Sibai B, Dekker G, kupferminc M. Pre-eclampsia Lancet 2005:365(9461); 785-99

13. Silva LM ,Coolman M,Steegers EA, Jaddoe VW, Moll HA, Hofman A, Mackenbach-JP, Raat H. Low socioeconomic status is a risk factor for preeclampsia 2008jun, 26(6) Page no (111)

14. Sibai BM, Hypertension in pregnancy, In: Gabbe SG, Niebyl JR, Simpson JL, editors. Obstetrics: normal and problem pregnancies. $5^{\text {th }}$ edn. Churchill Livingston, New York: 1996, Page no (935-996)

15. Adibelli Z, Dilek M, AKpolat T.Lemon juice as an alternative therapy in hypertension.2008 Jun 26:135(2). 